\title{
Stereoselective Synthesis of trans-2,6-Disubstituted Dihydropyrans through Intramolecular Allylic Transfer Reaction ${ }^{\dagger}$
}

\author{
Chan-Mo Yu, Mi-Sook Shin, and Eun-Young Cho \\ Deparment of Chemistry and Laboratory for Metal-Catalyzed Reactions. Sunghwmhitan Cniversity. Sumon $4+10-746$, Korea \\ Received Mav 18, 2004
}

Key Words : Cyclization. Dihydropỵran. Diastereoselectivity. Lewis acid. Titanium

During the course of our research program aimed at funding new synthetic methods for the stereoselective construction of tetrahydropyran units, we becanle quite interested in the utilization of 1 as a starting material for the stereoselective synthesis of 2.6-disubstituted $t / m \%$-dihydropyran 2 through a Lewis acid catalyzed allylic transfer reaction as illustrated in Scheme 1. The background behind this current study was the availability of enantionerically enriched 1 from the method developed by our laboratory. ${ }^{2}$ This process related to the well established Prins cyclization reactions of homoallylic alcohols with aldehydes. which provide always cis-2,6-disubstituted dihydropyrans prefer-

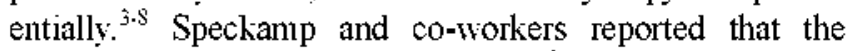
oxonium ion 6 of specific aldehyde $\left(\mathrm{R}^{2}=\mathrm{CO}_{2} \mathrm{Me}\right)$ could be an intermediate for the conversion to $/ \% m s-3$ in moderate diastereoselectivies, $2-5: 1 .{ }^{9}$ Owing to the strong stereoelectronic preference for the trimethylsilyl group to adopt an axial position in the reaction intermediate 6 derived from 5 through oxa-Cope rearrangement that develop carbocationic character at the $\beta$-position, it was expected that the conversion could provide the trans-2,6-disubstituted dihydropyran 3 in stereoselective manner. However. Roush and co-workers found that the same intermediate 6 from $\beta$ hydroxylallylsilanes with normal aldehydes produced $c i s$ dilydropyran + as a major component rather than transdihydopyran 3. ${ }^{\text {li }}$ Therefore. it was envisaged that the realization of efficient catalytic method for the synthesis of trans-2.6-disubstituted dihydropyran 3 from 1 with normal aldehydes under appropriate Lewis acid conditions could be useful because this method might be valuable for the synthesis of bioactive natural products. ${ }^{11}$ We report herein our discovery of the diasetreoselective formation of trans2,6-disubstituted dihydropyran 3 from 1 under Lewis acidic conditions with reasonable stereoselectivities.

The first study for preliminary experiments focused on the feasibility of 1 and 2 for the cyclization with achiral aldehydes promoted by a Lewis acid catalyst. To investigate the sequence outlined in Scheme 1, the cyclization began with TMS ethers $1 \mathbf{a}$ and $\mathbf{2 a}$ as starting materials. ${ }^{12}$ Initial attempts at the cyclization of $1 \mathbf{a}$ and $2 \mathrm{a}$ with hydrociunamaldehyde ( 2 equiv) under TMSOTf $\left(0.5\right.$ equiv) at $-78^{\circ} \mathrm{C}$ in

Dedicated to Professor Yong Hae Kim in admiration of his contributions to organic chemistry

'Corresponding Author: Tel: -82-31-290-7067; Fax: -82-31-290-

7075: e-mail: enylua chem.skkll.ac.kr

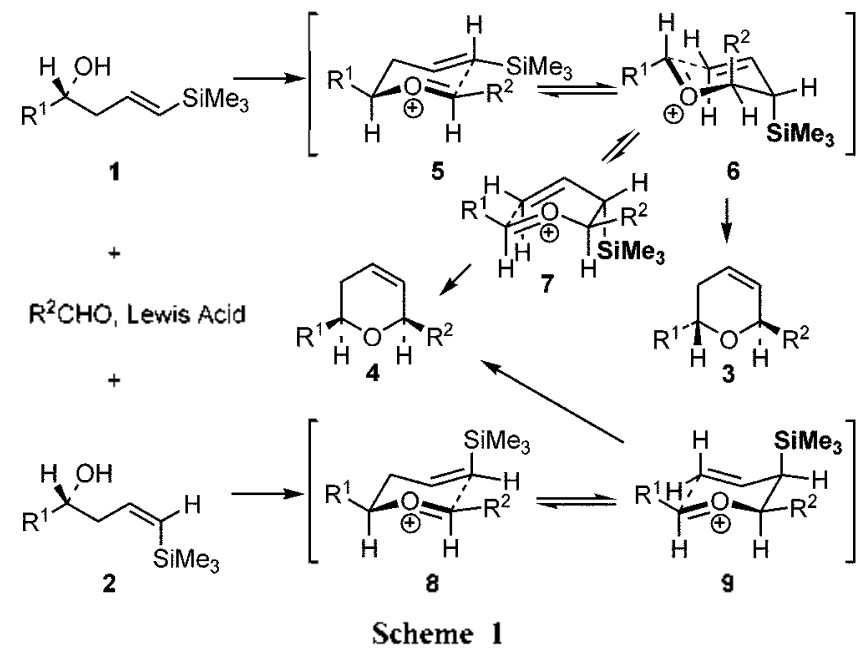

$\mathrm{CH}_{2} \mathrm{Cl}_{2}$ indicated that the conversion into the dihydropyran could be realized. but the reaction produced the same cisdihydropyran ta as a major component with good diastereoselectivity in moderate chemical yields as indicated in Table 1. The preferential formation of the cis-dihydropyran ta from 1a can be explained by the favour of boat-like stereochemical model 7 over chair-like model 6 mainly due to the steric bias as depicted in Scheme 1 . We subsequently speculated that bigger counter anion in internediates 6 and 7 might be a control factor to regulate stereochemical pathways. ${ }^{1}$ Attempts to develop more efficient Lewis acids by modification of the triflate ion with the more bulky and electron withdrawing counter anion such as bis(trifluorometlyylsulfonyl)amide $\left[\mathrm{MN}\left(\mathrm{SO}_{2} \mathrm{CF}_{3}\right)_{2}, \mathrm{MNTf}_{2}\right]^{13}$ afforded encouraging but only marginal results-- although compound 2a afforded cis-dilydropyran ta almost exclusively, compound 1a produced a $1: 3$ mixture of the diastereomers as shown in Table 1 (entries 3 and 4).

In order to improve reaction conditions in terms of chemical conversion and stereoselectivity. an intramolecular reaction of the $\alpha$-acetosy acetal 10 was considered inmediately. The $\alpha$-acetoxy acetals 10 were prepared by the method described by Rychnovshy for in situ acylation of the tetrahedral intermediates generated by DIBAL reduction of corresponding esters. ${ }^{14}$ Compound 10a $\left(\mathrm{R}^{1}=\mathrm{PhCH}_{2} \mathrm{CH}_{2}, \mathrm{R}^{2}\right.$ $=\mathrm{CH}_{3}$ ) was chosen as a model compound. After surveying numerous conditions with a variety of Lewis acids, several key fundings were emerged: i) reaction of $\mathbf{1 0 a}$ in the presence 
Table 1. Preliminary investigations for intramolecular allylic transsfer reactions

\begin{tabular}{|c|c|c|c|c|c|}
\hline Entry & $1 a$ or $2 a$ & Lewis acid & Time, h & $\operatorname{dr}(3 \mathbf{a}: 4 \mathbf{a})^{a}$ & Yield $(\%)^{b}$ \\
\hline 1 & $1 a$ & TMSOTf & 8 & $4: 96$ & 44 \\
\hline 2 & $2 a$ & (50) $\mathrm{mol} \%$ ) & 8 & $3: 97$ & $5 \hat{3}$ \\
\hline 3 & 1a & TMSNTE & 8 & $24: 74$ & 67 \\
\hline 4 & $2 a$ & (30 $\mathrm{mol} \%$ ) & 8 & $1:>99$ & 72 \\
\hline 5 & $1 a$ & $\mathrm{Me}_{2} \mathrm{AlNTf}_{2}$ & 6 & $44: 56$ & 71 \\
\hline 6 & $2 a$ & (30 $\mathrm{mol} \%$ ) & 6 & $1:>99$ & 78 \\
\hline 7 & $1 \mathrm{a}$ & $(\mathrm{P} T \mathrm{O})=\mathrm{Ti}(\mathrm{NTt})=$ & 5 & $78: 22$ & 77 \\
\hline 8 & $2 a$ & (30 $\mathrm{mol} \%$ ) & 5 & $1:>99$ & 75 \\
\hline
\end{tabular}

"Determined by analysis of $500 \mathrm{MHz}{ }^{~} \mathrm{H}$ NMR spectra. ${ }^{b}$ Yields refer to isolated and purified yield.

of $(\mathrm{PrO})_{2} \mathrm{Ti}(\mathrm{NTf})_{2}$ occurred readily at $-78{ }^{\circ} \mathrm{C}$ : this Lewis acid was generally superior to other Lewis aicds such as $\mathrm{SnCl}_{4}, \mathrm{BF}_{3} \cdot \mathrm{OEt}_{2}$, TMSOTf. TMSNTf $30 \mathrm{~mol} \%$ of $(i \mathrm{PrO})_{2} \mathrm{Ti}(\mathrm{NTf})_{2}$ required for optinal conditions in terms of chemical yields and reaction rates; iii) reaction performed at $-78^{\circ} \mathrm{C}$ in $\mathrm{CH}_{2} \mathrm{Cl}_{2}$ resulted in the best chemical yields and stereoselectivities in comparison with other solvents such as toluene, THF. and $\mathrm{PhCF}_{3}$ : iv) diastereomeric ratio turned out to be $91: 9$ as deternined by the analysis of ${ }^{1} \mathrm{H}$ NMR of crude products. Under optimal conditions (entry $\mathrm{I}$ in Table 2), the reaction was conducted by dropwise addition of $(\mathrm{iPrO})_{2} \mathrm{Ti}(\mathrm{NTf})_{2}(30 \mathrm{~mol} \%)$ in $\mathrm{CH}_{2} \mathrm{Cl}_{2}$ at $-78^{\circ} \mathrm{C}$ to a stirred solution of $10 \mathrm{a}$ in $\mathrm{CH}_{2} \mathrm{Cl}_{3}$. After $5 \mathrm{~h}$ at $-78^{\circ} \mathrm{C}$, usual work up and chromatography gave 3 a along with 4 a in $81 \%$ yield.

With the notion that this approach might lead to a general and efficient method for the synthesis of trans-2.6dihydropyran 3. we set out to determine the substituent effects with several 10 to produce structurally various products. Indeed. the method is successful with $\mathbf{1 0}$ to yield the trans-2.6-disubstituted pyrans 3 in moderate to high diastereoselectivities as it can be seen in Table 2. We observed that better diastereoselectivities and chemical yields were obtained with less hindered substituents of $R^{2}$ in 10 compared to more hindered substituents. It is worthy note that the enantiomerically enriched starting compound (10a. $93 \%$ e) produced the optically active product (3a $92 \%$ ee) without loosing optical purity as judged by HPLC analysis using chiral column (Chiracel. OJ-H).

In summary this paper describes a novel procedure for the stereoselective synthesis of trans-2.6-disubstituted pyrans 3 from the $\alpha$-acetoxy acetal $\mathbf{1 0}$ catalyzed by $(\mathrm{PrO})_{2} \mathrm{Ti}(\mathrm{NTf})_{2}$ in a general and efficient way, which promises to be widely' useful. The chemical transformation involves the oxa-Cope rearrangement and subsequent imtramolecular allylic transfer reaction into the oxonium ion. Further studies including synthetic applications and more detail mechanistic pathway are in progress.
Table 2. Cyclization of 10 with (iPrO) $)_{2} \mathrm{Ti}(\mathrm{NTf})_{2}$ to trans-dihydropyran $3 \mathfrak{a}^{a}$

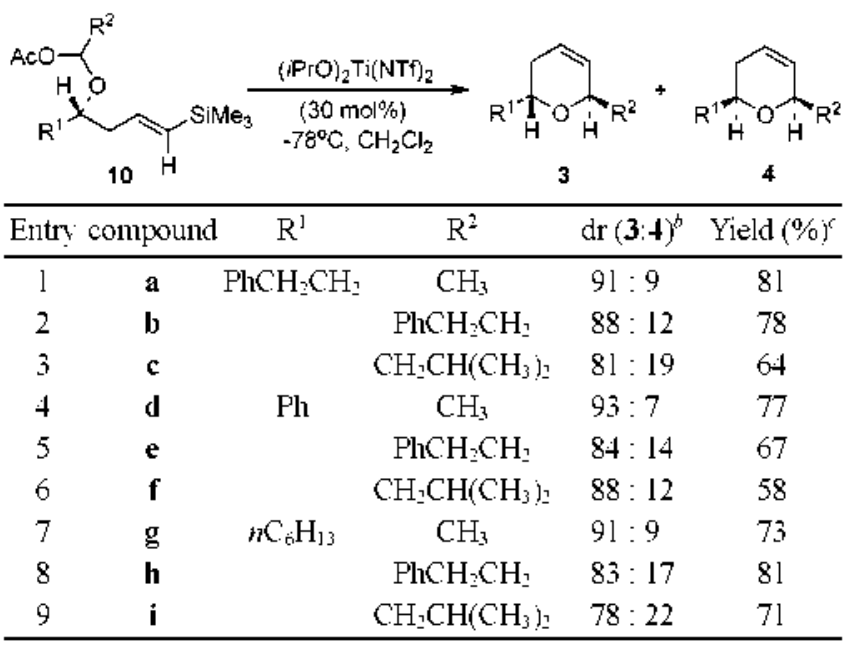

"All reactions were carried out with 30 mol! of $(i \operatorname{PrO})_{2} \mathrm{Ti}(\mathrm{NTt})$ at -78 ${ }^{6} \mathrm{C}$ for $5 \mathrm{~h}$ in $\mathrm{CH}_{2} \mathrm{Cl}_{2}$. ${ }^{b}$ Determined by the analysis of $500 \mathrm{MHz}{ }^{1} \mathrm{H}$ NMR spectra. 'Yields refer to isolated and purified yield.

Acknowledgment. Generous financial support by grants from the Korea Ministry of Science and Teclunology through the National Research Laboratory program and the Center for Molecular Design \& Synthesis (CMDS: KOSEF SRC) at KAIST is gratefully acknowledged.

\section{References and Notes}

1. Yu. C.-M.: Lee, J.-Y:; So, B.: Hong, J. Angew: Chent Int. Ed. 2002. 41,161

2. Yu. C.-M.: Kim. J.-M:- Shin, M.-S.; Yoon, M.-O. Chem. Connum. 2003. 1744 .

3. Viswanathan. G. S: Yang. J.: Li. C.-T. Organic Lett. 1999. 1. 933.

4. Cloninger. M. J.: Ovenman, L. E. J. Am. Chent Soc, 1999, 121 . 1091 .

5. Rychnovshy. S. D.: Hu, Y: Ellsworth, B. Tetrahedron Lett 1998. 39.7271 .

6. Marko. I.: Chelle. F. Tetrahedron Lett 1997. 38. 2895

7. (a) Marko. I. E.: Mekhalfia. A.: Bayston. D. T.: Adams. H. J. Org. Chent 1992. 57, 2211. (b) Marko. I. E.: Plancher, J.-M. Tetrahedron Lett. $1999,40.5259$

8. Coppi. L.: Ricci, A.; Taddei. M. J. Org. Chem. 1988. 53.911.

9. (a) Semeyn. C.: Blaauw. R. H.: Hiemstra. H.: Spechamp. W. N. $J$. Org. Chent 1997. 62. 3426. (b) Lolkema. L. D. M.: Semeyn. C.: Asheek. L.: Hiemstra. H.: Spechamp. W. N. Tetrahedron 1994. 50. 7129 .

10. Roush, W. R: Dilley, G. J. Symlett 2001,956.

11. (a) Evans, D. A.; Cee, V. J.: Smith. T. E.; Santiago, K. J. Organic Lett. 1999. 1. 87. (b) Rychtovshy. S. D.: Thomas. C. R. Organic Lett. 2000. 2. 1217.

12. Compound 2 was prepared from the corresponding homo propargyl alcohol by two step secpuence: 1) i) $n \mathrm{BuLi}$ (2.2 quiv). THF $-78^{\circ} \mathrm{C}$ ii) TMSCl (2.2 euiv) iii) $\mathrm{H}_{3} \mathrm{O}^{+}$2) Ni-B, $\mathrm{H}_{2}$. see: $\mathrm{Yu}$. C.-M.: Yoon, S.-K: Choi. H.-S.: Baek, K. Chem Commun 1997. 763

13. (a) Marx. A.: Yamamoto. H. Angew. Chemt. Int Ed 2000. 39. 178. (b) Mathieu. B.: Ghosez. L. Tetrahedron Lett. 1997. 38. 5497. (c) Mikami. K.: Kotera, O.: Motoyama. Y.; Sakaguchi, M.: Maruta. M. Synlett 1996. 171.

14. Kopechy, D. J.; Rychnovsky, S. D. J. Org Chem 2000, 65, 191 